\title{
Brain-adipose tissue cross talk
}

\author{
Timothy J. Bartness*, C. Kay Song, Haifei Shi, Robert R. Bowers and Michelle T. Foster \\ Department of Biology, Neurobiology \& Behavior Program, Center for Behavioral Neuroscience, \\ Georgia State University, Atlanta, GA 30302-4010, USA
}

\begin{abstract}
While investigating the reversible seasonal obesity of Siberian hamsters, direct sympathetic nervous system (SNS) postganglionic innervation of white adipose tissue (WAT) has been demonstrated using anterograde and retrograde tract tracers. The primary function of this innervation is lipid mobilization. The brain SNS outflow to WAT has been defined using the pseudorabies virus (PRV), a retrograde transneuronal tract tracer. These PRV-labelled SNS outflow neurons are extensively co-localized with melanocortin-4 receptor mRNA, which, combined with functional data, suggests their involvement in lipolysis. The SNS innervation of WAT also regulates fat cell number, as noradrenaline inhibits and WAT denervation stimulates fat cell proliferation in vitro and in vivo respectively. The sensory innervation of WAT has been demonstrated by retrograde tract tracing, electrophysiological recording and labelling of the sensory-associated neuropeptide calcitonin gene-related peptide in WAT. Local injections of the sensory nerve neurotoxin capsaicin into WAT selectively destroy this innervation. Just as surgical removal of WAT pads triggers compensatory increases in lipid accretion by nonexcised WAT depots, capsaicin-induced sensory denervation triggers increases in lipid accretion of non-capsaicin-injected WAT depots, suggesting that these nerves convey information about body fat levels to the brain. Finally, parasympathetic nervous system innervation of WAT has been suggested, but the recent finding of no WAT immunoreactivity for the possible parasympathetic marker vesicular acetylcholine transporter (VAChT) argues against this claim. Collectively, these data suggest several roles for efferent and afferent neural innervation of WAT in body fat regulation.
\end{abstract}

Sympathetic nervous system: Sensory nerves: Parasympathetic nervous system: Pseudorabies virus: Lipolysis

A critical ability of all animals is to meet energy demands quickly with utilizable metabolic fuels. In mammals glycogen serves as a rapidly available, but extremely limited, carbohydrate energy source. Energy is predominately stored as lipid in white adipose tissue (WAT) in the form of triacylglycerol (Newsholme \& Leech, 1983). Access to this energy in fat can be mediated by several means, principally by the sympathetic nervous system (SNS) innervation of WAT. The present review starts by discussing the SNS innervation of WAT and then considers its sensory innervation and possible parasympathetic nervous system (PSNS) innervation. As the title of the review suggests, the cross talk occurring between the brain and WAT, which use these innervations as conduits, will be highlighted. However, the provocative and interesting cross talk between WAT and the brain that occurs via humoral factors will not be discussed.

\section{Adrenal medullary catecholamines, once thought to be the principal stimulators of lipid mobilization, do not play a major role in lipolysis}

Traditionally, adrenal medullary secretion of catecholamines, primarily adrenaline, is thought to be the underlying means by which lipid mobilization is stimulated. Thus, signals indicating the need for lipid-derived energy activate brain sites that, in turn, increase the SNS outflow to the intermedial lateral horn of the spinal cord impinging on the sympathetic preganglionic neurons that reside there. These neurons project separately to adrenaline- and 
noradrenaline-synthesizing chromaffin cells in the adrenal gland (Hillarp \& Hokfelt, 1953; Edwards et al. 1996), and when their neuronal activity increases, there is an increase in the release of adrenaline, and to a lesser extent noradrenaline, into the circulation. Circulating adrenaline, in turn, stimulates membrane-bound WAT adrenoceptors (for review, see Lafontan \& Berlan, 1993). Stimulation of these $\beta$-adrenoceptors activates a cascade of lipolytic intracellular steps resulting in increases in lipolysis (the breakdown of triacylglycerols into glycerol and NEFA), thereby supplying the needed lipid-derived fuels for oxidation (Newsholme \& Leech, 1983). Despite mounting functional and histological evidence to the contrary (for reviews, see Bartness \& Bamshad, 1998; Bartness et al. 2001), the dogma that adrenaline is the principal stimulator of lipolysis persists. This view probably arises because of the robust lipolytic activity of adrenaline when added to isolated adipocytes in vitro (for example, see White \& Engel, 1958; Rizack, 1961). Evidence contrary to the primacy of adrenaline in triggering lipolysis in vitro is the inability of adrenal demedullation to block lipid mobilization triggered by several physiological conditions in vivo, e.g. glucoprivation (Nishizawa \& Bray, 1978), electrical stimulation of the medial hypothalamus (Takahashi \& Shimazu, 1981) and short photoperiod exposure in Siberian hamsters (Phodopus sungorus; Demas \& Bartness, 2001b). As described later (p. 54), it is now more commonly believed that the sympathetic innervation of WAT, through the release of its primary postganglionic neurotransmitter noradrenaline, is the principal initiator of lipolysis (for review, see Bartness \& Bamshad, 1998; Bartness et al. 2001; Dodt et al. 2003).

\section{Naturally-occurring seasonal decreases in Siberian hamster body fat levels have served as a useful model to study the role of the sympathetic nervous system innervation of white adipose tissue}

Although the innervation of WAT by the SNS has received support both neuroanatomically and functionally for more than 100 years (Dogiel, 1898; for review, see Bartness \& Bamshad, 1998), it has only been in the last decade that irrefutable neuroanatomical and functional data have been forthcoming. The scientific community turned a blind eye toward this notion, probably because of the vigorous lipolytic response elicited by adrenaline when added to isolated adipocytes in vitro, as discussed earlier, and because initially only SNS innervation of blood vessels was seen in WAT (Wirsen, 1964; Daniel \& Derry, 1969; Ballantyne \& Raftery, 1974). This latter conclusion was undoubtedly drawn because white adipocytes of ad libitum-fed animals are filled with a single large lipid droplet that pushes the cell membranes into tight contact with neighbouring adipocytes, obfuscating the parenchymal space. After fasting, however, the cells shrink, revealing catecholaminergic innervation of both the vasculature and white adipocytes using histofluorescence (Diculescu \& Stoica, 1970; Ballard et al. 1974; Slavin \& Ballard, 1978; Rebuffe-Scrive, 1991).

A contribution to these more compelling data has been made through the present authors' search for the mechanisms underlying the reversibility of seasonal (photoperiod-induced) obesity exhibited by Siberian hamsters (for reviews, see Bartness \& Wade, 1985; Bartness et al. 2002). As many of the neuroanatomical and functional examples of WAT innervation contained herein are based on these findings with the Siberian hamster, this model, which drew the authors into the 'brain-adipose tissue cross talk', will be briefly described.

When housed in long 'summer-like' days Siberian hamsters show a marked seasonal obesity (40-50\% body fat) that gradually and naturally develops across the first 1-2 months of life (for review, see Bartness \& Wade, 1985). Most remarkably, this obesity is completely reversible, such that when they are exposed to short 'winter-like' days (SD) they voluntarily rapidly lose body fat, with no decrease in food intake during the period of most rapid body mass decrease (for example, see Wade \& Bartness, 1984; Bartness et al. 1989). The day length (photoperiod) provides a reliable 'noise-free' environmental cue (Turek \& Campbell, 1979) that is responsible for the seasonal changes in body fat and other annual responses (e.g. pelage colour change, reproductive status, thermogenic capabilities) in Siberian hamsters, as well as in other species showing photoperiod-driven seasonal cycles (for review, see Underwood \& Goldman, 1987; Bartness \& Goldman, 1989). This photic information is received by the retina and transmitted via a multi-synaptic pathway to the pineal gland, where the pinealocytes synthesize and secrete melatonin (MEL) only at night. Thus, changes in the duration of the nocturnal secretion of pineal MEL faithfully code the night length, thereby signalling the progression of the seasons (photoperiods). Pinealectomized hamsters given exogenous peripheral MEL infusions that mimic the natural peak duration of nocturnal MEL secretion trigger the photoperiodic responses, including the changes in body fat (Bartness \& Goldman, 1988; Song \& Bartness, 1996, 1998).

Initially a hormonal intermediary for the MEL-induced changes in body fat was sought; however, none of the hormones that change seasonally and that also directly or indirectly affect body fat (e.g. thyroxine, insulin, gonadal steroids) could account for the SD-induced decreases in lipid stores (for review, see Bartness \& Fine, 1999; Bartness et al. 2002). Thus, the SNS was considered as a possible mediator for the photoperiod-MEL-induced changes in body fat.

\section{There is neuroanatomical and functional evidence for the sympathetic nervous system innervation of white adipose tissue}

The inability of adrenal demedullation to block lipid mobilization under several physiological conditions (see $\mathrm{p}$. 54) led to the examination of the SNS innervation of WAT as a possible mediator of the SD-induced decrease in body fat shown by Siberian hamsters (Demas \& Bartness, 2001b). The first direct neuroanatomical evidence for the sympathetic postganglionic neurons was provided through injections of a retrograde fluorescent tract tracer FluoroGold into inguinal WAT or epididymal WAT. To demonstrate these connections bi-directionally, an anterograde fluorescent tract tracer DiI was also injected into the 
sympathetic chain (Youngstrom \& Bartness, 1995). Fluorescently-labelled cell bodies were found in the sympathetic chain as a result of retrograde labelling of the postganglionic nerves and rings of fluorescence around individual adipocytes as a result of anterograde labelling (Youngstrom \& Bartness, 1995). Moreover, the distribution of postganglionic neurons innervating these two fat pads was found to be quite distinct, providing a likely neuroanatomical basis for the SD-induced differential lipid mobilization across fat pads (for example, see Bartness et al. 1989; Bartness, 1995, 1996), as well as for fat pad-specific differences in lipolysis shown in other rodent species and in human subjects. These data, along with an anecdotal report of sympathetic nerves innervating both white adipocytes and blood vessels, as revealed by histofluorescence combined with confocal microscopy (RebuffeScrive, 1991), support the view that white adipocytes are sympathetically innervated. This phenomenon is not species-specific because, in addition to the studies of the SNS innervation of Siberian hamster WAT, parallel experiments were conducted in laboratory rats yielding similar findings (Youngstrom \& Bartness, 1995).

These earlier studies gave no indication of the origins of the SNS outflow from brain to WAT. Connections from specific brain nuclei to WAT were, up to that time, inferred from lesion or stimulation studies in which the target site was destroyed or chemically or electrically stimulated and resulting changes in WAT growth or physiology were ascribed to disruption or activation of the presumed SNS outflow connections to WAT (for review, see Bartness \& Bamshad, 1998). Another credible alternative explanation for the effects of brain lesions or stimulation on WAT would be that these manipulations affect peripheral endocrine organ function (e.g. PSNS innervation of the pancreas affecting insulin or glucagon secretion) resulting in changes in hormonal secretion that, in turn, affect WAT growth and/or physiology. In order to determine the credibility of the post hoc explanations ascribing the effects of brain lesion or stimulation to alterations in the SNS outflow to WAT, a transneuronal tract tracer, the Bartha's $\mathrm{K}$ strain of the pseudorabies virus (PRV), was used. PRV had been developed by other researchers to trace entire circuits within the same animal and had been used successfully to show the SNS outflow to the adrenal gland (Strack et al. 1989) among other peripheral tissues. Neurotropic viruses, such as the PRV, bind specifically to presynaptic neural membranes, fuse with their axonal membrane and deliver the uncoated capsids inside the axon. The capsids are transported by retrograde motors (probably dynein) to the cell body, where they replicate (Enquist \& Card, 2003). The virus only exits the infected neurons via their dendrites, only infecting neurons that are synaptically connected to these PRV-laden cells. This process results in the retrograde labelling of functional chains of hierarchically-connected neurons within an animal (Card et al. 1990; Strack \& Loewy, 1990). Initially PRV was injected into the inguinal WAT and epididymal WAT of Siberian hamsters (Bamshad et al. 1998). Retrogradely-infected cells were identified using immunocytochemistry throughout the neural axis, including the spinal cord (intermediolateral cell group, central autonomic nucleus), the brainstem (nucleus of the solitary tract, A5 regions and the $\mathrm{C} 1 /$ rostroventrolateral, rostroventromedial and caudal raphe nuclei/areas), midbrain (periaqueductal gray) and forebrain (hypothalamic: arcuate nucleus, dorsal, lateral, paraventricular, suprachiasmatic, nuclei and medial preoptic area; non-hypothalamic: zona incerta, medial amygdala, septum and bed nucleus of the stria terminalis; Bamshad et al. 1998). Many of the virus-labelled brain sites comprising the sympathetic outflow to WAT had been correctly deduced as components of this circuit using lesion or stimulation approaches (for review, see Bartness \& Bamshad, 1998), except for one glaring omission, the virtual lack of PRV-labelled neurons in the ventromedial hypothalamic nucleus, an area implicated in dozens of lesion or stimulation studies (for review, see Bartness \& Bamshad, 1998). This misplaced focus on the ventromedial hypothalamic nucleus probably occurred because manipulations of the ventromedial hypothalamic nucleus secondarily affect paraventricular nuclei descending pathways that pass adjacent to the ventromedial hypothalamic nucleus on their way to their brainstem and spinal cord destinations (for example, see Gold, 1973; Gold et al. 1977; Luiten et al. 1985).

\section{Regulators of sympathetic outflow}

A multitude of virally-labelled structures across the neuroaxis appears following the PRV injections into WAT (Bamshad et al. 1998, 1999; Shi \& Bartness, 2001; Song \& Bartness, 2001) and, moreover, within each of these structures there are scores of PRV-infected neurons. It seems unlikely that all these neurons in all these structures are activated under all conditions of lipid mobilization (e.g. with fasting, cold exposure or exercise). Instead, it is hypothesized that subsets of these structures and/or subpopulations of neurons within each structure are activated by different lipolytic stimuli. This hypothesis cannot be tested using double labelling for c-fos (the early immediate gene product that serves as a marker of cell activation; Hoffman et al. 1993) in these PRV-labelled circuits because the virus itself induces c-fos during early neuronal infection (Ozaki et al. 1996; Weiss \& Chowdhury, 1998). A different approach was therefore used in an attempt to determine which of the SNS outflow neurons to WAT are involved in the SD-induced increased lipid mobilization. To label these neurons, in situ hybridization for MEL receptor mRNA combined with PRV labelling of the SNS outflow to WAT was used (Song \& Bartness, 2001). As MEL does not directly affect lipolysis of isolated WAT cells in vitro ( $\mathrm{Ng} \&$ Wong, 1986), it was reasoned that there should be MEL receptors located on SNS outflow neurons to WAT of Siberian hamsters. First the SNS outflow neurons to WAT were labelled using PRV injected into inguinal WAT, combined with in situ hybridization for the $\mathrm{MEL}_{1 \mathrm{a}}$ receptor, the subtype through which the photoperiod causes seasonal responses in this and other species (Song \& Bartness, 2001). Double-labelled neurons were found in several brain regions, including the suprachiasmatic nuclei (Fig. 1), an area previously shown to be critical for reception of the photoperiod-encoded MEL 


\section{$M E L_{1 a}$ receptors are co-localized on SNS outflow neurons to WAT}

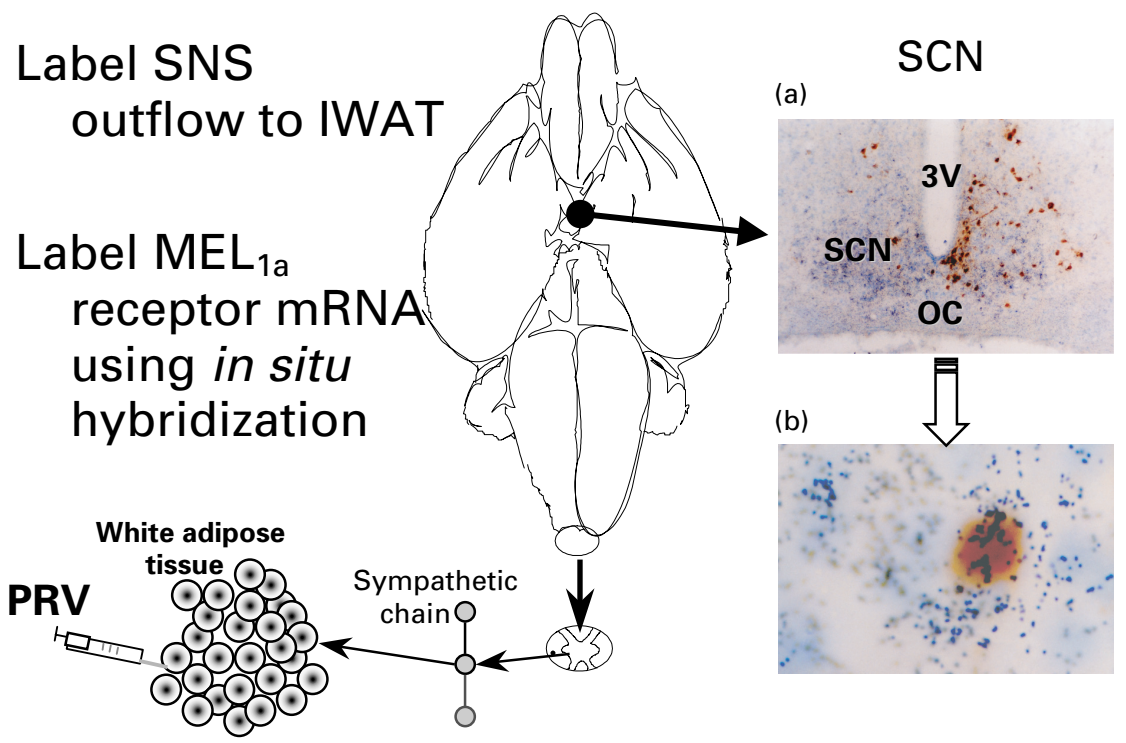

Fig. 1. Schematic representation of the double labelling of white adipose tissue (WAT) sympathetic nervous system (SNS) outflow neurons that also express mRNA for the functional melatonin receptor ( $\mathrm{MEL}_{1 \mathrm{a}}$ ) in Siberian hamsters (Phodopus sungorus) using the pseudorabies virus (PRV) and in situ hybridization respectively. The diagram is a coronal section of the brain at the level of the ventral hypothalamus showing double labelling of sympathetic outflow neurons to WAT with melanocortin-4 receptor (MC4-R) gene expression in the suprachiasmatic nuclei (SCN). (a) Brown staining indicates PRV labelling and the dark blue staining indicates gene expression for the MC4-R. (b) Enlarged photomicrograph shows one PRV-labelled neuron, as indicated by the brown staining, containing MC4-R mRNA, as indicated by the dark blue staining. 3V, third ventricle, OC, optic chiasm. (Adapted from Song \& Bartness, 2001.)

signals that trigger SD responses (Bartness et al. 1991; Song \& Bartness, 1998). Thus, the following scenario of SD-induced lipid mobilization has emerged. The increases in the duration of nocturnal MEL secretion resulting from the increases in night length cause increases in the stimulation of $\mathrm{MEL}_{1 \mathrm{a}}$ receptors in some of the neurons comprising the sympathetic outflow to WAT (e.g. suprachiasmatic nuclei). This, in turn, causes increases in the sympathetic drive to WAT (seen as an increase in noradrenaline turnover; Youngstrom \& Bartness, 1995) thereby increasing lipolysis. Increased lipolysis, in turn, leads to decreases in WAT pad mass, reflected as decreased fat cell size (Bartness, 1996; Mauer \& Bartness, 1996). To the authors' knowledge, this condition is the only one in which a stimulus that increases lipolysis can be traced from the environment to the adipocyte. Although the relevance for human obesity of photoperiod-MEL-induced changes in body fat is unknown, this model of naturally-occurring changes in body fat has proven useful in understanding the SNS neuroanatomy underlying lipid mobilization.

Using this powerful methodology for co-labelling central WAT SNS outflow neurons with expression of mRNA for their receptors, the possibility that melanocortin-4 receptor subtype (MC4-R) gene expression is co-localized with the brain sympathetic circuits innervating WAT has recently been tested. Although the melanocortins have been shown to markedly affect food intake and thermogenesis (for review, see Butler \& Cone, 2002), their involvement in SNS-mediated lipolysis has been implied, but not directly tested. Chronic central administration of a synthetic MC4$\mathrm{R}$ agonist melanotan-II (Haskell-Luevano et al. 1994) decreases WAT pad mass by approximately $50 \%$, even when using pair-fed controls to account for its ability to decrease food intake (Raposinho et al. 2003). These results indicate that the melanotan-II-triggered decreases in body fat cannot be accounted for simply by its ability to decrease food intake. Furthermore, centrally-applied melanotan-II decreases the RQ, suggesting that lipid-derived fuels are being oxidized (Hwa et al. 2001). These and other data prompted the authors to test whether MC4-R mRNA is colocalized with PRV-labelled SNS outflow neurons to WAT in Siberian hamsters (CK Song, D Richard and T Bartness, unpublished results). Extensive co-localization of MC4-R mRNA with PRV-labelled SNS outflow neurons was found across the neural axis. All animals were found to have large numbers of PRV + MC4-R neurons in all PRVlabelled areas, including the paraventricular nuclei, preoptic area, bed nucleus of the stria terminalis and amygdala in the forebrain, periaqueductal gray in the midbrain and the nucleus of the solitary tract, lateral paragigantocellular 
nucleus, lateral reticular area, rostroventrolateral medulla and anterior gigantocellular nucleus in the brainstem, to name only a few of the more predominant co-localizations. This co-localization is the most extensive that has been seen in the work to date (Shi \& Bartness, 2001; Song \& Bartness, 2001) or in studies in the literature (for brief review, see Discussion in Shi \& Bartness, 2001). These data suggest that MC4-R may play a prominent role in the modulation of SNS outflow neurons to WAT either through stimulation by the endogenous melanocortin agonist $\alpha$ melanocyte-stimulating hormone and/or through inhibition by the naturally-occurring melanocortin-3 receptor and MC4-R antagonist agouti-related protein (Ollmann et al. 1997). Collectively, studies such as this one, and the colocalization of $\mathrm{MEL}_{1 \mathrm{a}}$ receptor mRNA with PRV-labelled WAT SNS outflow neurons (Song \& Bartness, 2001), provide maps to guide future experiments for site-specific microinjections or implants designed to turn the WAT SNS outflow 'on' or 'off'.

\section{The sympathetic nervous system innervation of white adipose tissue has at least three functions: lipolysis, the regulation of fat cell number and control of some white adipose tissue-secreted proteins}

There are three recognized functions of the SNS innervation of WAT: (1) the principal initiator of lipolysis; (2) control of fat cell number; (3) control of some WATsecreted proteins. The literature relating to the role of the SNS in lipolysis has recently been reviewed (Bartness \& Bamshad, 1998; Bartness et al. 2001) and, therefore, will only be considered briefly. Functional studies have been conducted that take advantage of the unilateral innervation of pairs of WAT pads. One of a pair of WAT pads can be denervated with its contralateral counterpart serving as a within-animal neurally-intact control, thereby keeping circulating factors, age, nutritional status and the behavioural activity the same between fat pads. Surgically-denervated WAT shows a greatly diminished lipid mobilization compared with its neurally-intact controls across a variety of lipolytic stimuli, e.g. fasting (Clement, 1950; Cantu \& Goodman, 1967; Bray \& Nishizawa, 1978) and oestradiol treatment of ovariectomized animals (Lazzarini \& Wade, 1991). Although local surgical denervation affords anatomical specificity compared with global sympathectomy using guanethidine (Powley et al. 1983) or 6-hydroxydopamine (Robidoux et al. 1995), it is not neuroanatomically selective because sympathetic and sensory nerves cannot be distinguished visually and therefore all types of nerves are severed. Indeed, surgical denervation decreases the immunoreactivity of tyrosine hydroxylase and calcitonin gene-related peptide (CGRP) -, indicating reduced sympathetic and sensory innervations respectively (Shi et al. 2005). A more selective approach than surgical denervation is chemical SNS denervation of WAT, which have been successfully accomplished using locally-injected guanethidine (Demas \& Bartness, 2001a,b) and, more recently with greater reliability, using locally-injected 6-hydroxy-dopamine (R Bowers, CK Song, H Shi and T Bartness, unpublished results). Guanethidine-induced local SNS denervation of WAT severely blunts the SD-induced increase in lipid mobilization (Demas \& Bartness, 2001b), as does surgical denervation (Youngstrom \& Bartness, 1998), although only a complete blockade is achieved when adrenal demedullation is also added (Demas \& Bartness, $2001 b$ ).

Recently, cross talk between white adipocytes and sympathetic neurons that influence lipolysis has been demonstrated cleverly and simply in vitro by co-culturing 3T3-L1 cells and rat superior cervical ganglia postganglionic sympathetic neurons (Turtzo et al. 2001). Characteristic morphology associated with each cell type, as well as cell type-specific markers, occurs in this situation, attesting to the authenticity of each cell type (Turtzo et al. 2001). Sympathetic neurons co-cultured with these adipocytes markedly inhibit $\beta$-adrenoceptor-stimulated lipolysis and leptin secretion (Turtzo et al. 2001). The effect on lipolysis is likely to be a result of increases in the release of neuropeptide $\mathrm{Y}$ by the co-cultured sympathetic neurons (Turtzo et al. 2001); neuropeptide $\mathrm{Y}$ is known to inhibit lipolysis in vitro (Castan et al. 1994) by stimulating membrane-bound adipocyte peptide YY receptors (i.e. neuropeptide Y receptors; Castan et al. 1993). The inhibition of WAT leptin release also may be initiated by stimulation of these receptors.

\section{Sympathetic nervous system drive to white adipose tissue is not necessarily uniform across fat pads}

How the SNS outflow is directed across sympathetic targets in general (for review, see Morrison, 2001; Sved et al. 2001), and across individual WAT pads specifically, is not well understood. It seems clear that the traditional theory proposed by Cannon (1939) of an 'all or nothing' activation of the SNS is inadequate to account for differential sympathetic drives across peripheral tissues. Thus, recent measures of SNS drive (noradrenaline turnover and electrophysiological activity of sympathetic nerves), as well as viral and non-viral tract tracing experiments, suggest that Cannon's (1939) hypothesis may represent the exception rather than the rule for activation of the SNS (for reviews, see Morrison, 2001; Sved et al. 2001). For example, the SNS control of blood flow to various vascular beds can occur independently of one another and of other organs (e.g. kidney and brown adipose tissue; Vague et al. 1980). In addition, in some conditions there are coordinated increases in sympathetic drives to two or more SNS target tissues, whereas in other conditions there are simultaneous increases to one of these targets and decreases to another. For example, with cold exposure noradrenaline turnover in brown adipose tissue (Young et al. 1982; Garofalo et al. 1996) and WAT (Garofalo et al. 1996) increases, but with fasting noradrenaline turnover in brown adipose tissue decreases and in WAT it increases (Migliorini et al. 1997). How the SNS drive to these two tissues types is regulated is a biological mystery. An additional puzzle is how the sympathetic drive across WAT pads (i.e. among inguinal WAT, epididymal WAT, retroperitoneal WAT etc.) is regulated. For example, noradrenaline turnover differs markedly across individual WAT pads of SD-exposed Siberian hamsters (Youngstrom \& Bartness, 1995). Another example of differential 
sympathetic drive across WAT pads comes from a recent preliminary study ( $\mathrm{H}$ Shi and $\mathrm{T}$ Bartness, unpublished results) in which acute glucoprivation was generated via injection of the glucose-utilization blocker 2-deoxy-Dglucose. In this case, 2-deoxy-D-glucose was found to markedly increase noradrenaline turnover in inguinal, retroperitoneal and dorsosubcutaneous WAT similarly, but does not alter epididymal WAT noradrenaline turnover (Fig. 2). These data suggest that acute glucoprivation causes differential sympathetic drive across WAT pads and further illustrates the phenomenon of the separate control of sympathetic drive across SNS target tissues. From a clinical perspective it is of paramount importance to determine the mechanisms underlying the differential mobilization of lipid from WAT, because the distribution of WAT is critical in relation to whether the secondary deleterious health consequences of obesity are manifested (Vague et al. 1980; Gasteyger \& Tremblay, 2002). Moreover, even with modest decreases in visceral fat these secondary health consequences markedly improve (Pasanisi et al. 2001; Janssen et al. 2002), suggesting that an ability to selectively mobilize lipid from internal WAT depots would be of considerable clinical importance.

\section{Sympathetic nervous system innervation of white} adipose tissue also regulates fat cell proliferation

In addition to lipolysis the SNS innervation of WAT also influences WAT cellularity. It has long been recognized that WAT hypercellularity is a hallmark sign of obesity in both man and other animals (for reviews, see Kirtland \& Gurr, 1979; Faust, 1984; Hausman et al. 2001). In addition, obesity typically is associated with decreases in SNS activity (for reviews, see Dulloo \& Miller, 1987;

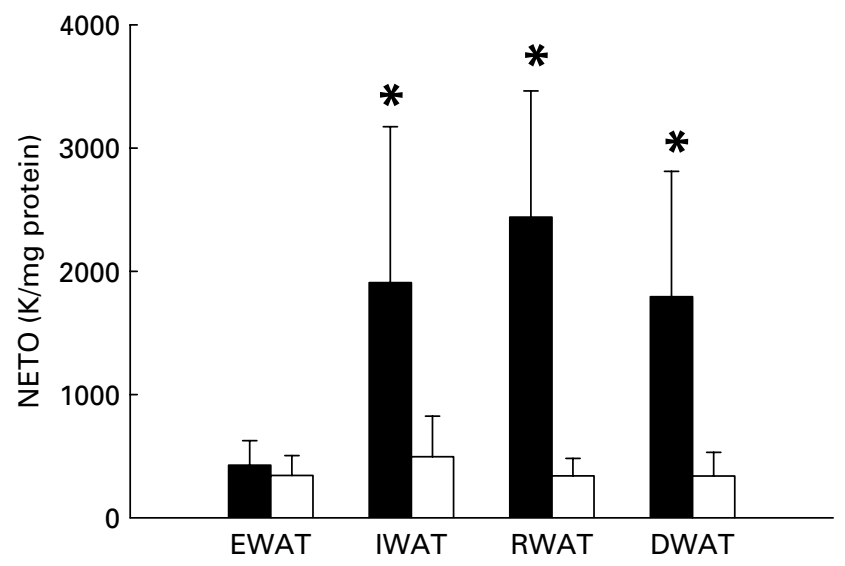

Fig. 2. Noradrenaline turnover (NETO) is differentially increased across white adipose tissue pads after glucoprivation induced by peripheral injections of 2-deoxy-D-glucose (2DG; $\mathbf{0})$ suggesting fat pad-specific control of sympathetic drive in Siberian hamsters (Phodopus sungorus). ( $\square$ ), Vehicle (saline; $9 \mathrm{~g}$ sodium chloride/l); IWAT, inguinal white adipose tissue; RWAT, retroperitoneal white adipose tissue; EWAT, epididymal white adipose tissue; DWAT, dorsosubcutaneous white adipose tissue. Values are means with their standard errors represented by vertical bars. Mean values were significantly different from those for the vehicle: ${ }^{*} P<0.05$. ( $\mathrm{H}$ Shi and T Bartness, unpublished results.)
Bray, 1990, 1991). It now appears that these two characteristics of obesity are related to one another; indeed, it may be hypothesized that decreases in SNS activity trigger hypercellularity. It appears that a high SNS drive to WAT inhibits, and a low SNS drive disinhibits (stimulates), fat cell proliferation, which was first demonstrated in vitro; noradrenaline added to white adipocyte precursor cells was found to inhibit their normal proliferation (Jones et al. 1992). This effect is blocked by pretreatment with the general $\beta$-adrenoceptor antagonist propranolol (Jones et al. 1992). Conversely, in Siberian hamsters (Youngstrom \& Bartness, 1998), and in laboratory rats (Cousin et al. 1993), it has been demonstrated that surgical denervation of WAT produces pronounced (approximately 2-fold) increases in fat cell number (FCN) with little change in fat cell size in vivo. In addition, it has recently been reported that the magnitude of the denervation-induced increase in FCN varies between fat pads, with marked increases occurring in inguinal WAT but no change in epididymal WAT (Shi et al. 2004). This differential increase in FCN by surgical denervation may reflect the natural propensity for these pads to grow by hyperplasia (inguinal WAT) $v$. hypertrophy (epididymal WAT; DiGirolamo et al. 1998). Recent preliminary data suggest that these increases in FCN probably represent real increases in fat cell proliferation, rather than filling of existing pre-adipocytes. Specifically, surgical denervation increases the number of bromodeoxyuridine-labelled cells (i.e. dividing cells) that also are immunoreactive for AD3, a white adipocyte-specific membrane protein (Wright \& Hausman, 1990; Kras et al. 1999), thus showing that they are proliferating white adipocytes (M Foster and $\mathrm{T}$ Bartness, unpublished results). Since surgical denervation severs all nerve types, it is possible that the lack of sensory innervation triggers increases in FCN. It has recently been found that WAT sensory denervation, accomplished by local injections of the sensory nerve neurotoxin capsaicin (Jansco et al. 1980; Ainsworth et al. 1981), and verified by decreased immunoreactivity for the sensory nerve-associated neuropeptide CGRP (Skofitsch \& Jacobowitz, 1985), does not increase FCN (Shi et al. 2004). Thus, decreases in the SNS drive to WAT appear to be a critical stimulus for increasing fat cell proliferation or FCN.

\section{What is the mechanism underlying the denervation- induced increase in fat cell number?}

If it were not for increases in $\mathrm{FCN}$, then there would be an upper limit to the extent of adiposity reached by human subjects and other animals; however, hypercellularity is a classic sign of obesity (Faust, 1984). Despite the pivotal role played by fat cell proliferation in the obese state, little is known about the mechanisms underlying the process (for review, see Hausman et al. 2001), especially compared with the knowledge of factors that contribute to the process of fat cell differentiation. One obvious potential mechanism by which the SNS modulates FCN or proliferation is via the stimulation of $\beta$-adrenoceptors on adipocyte precursor cells. Evidence that noradrenaline prevents normal proliferation through $\beta$-adrenoceptors in vitro is the ability of the general $\beta$-adrenoceptor blocker propranolol to 
disinhibit the noradrenaline-induced inhibition (Jones et al. 1992), as discussed earlier. Another adrenoceptor subtype, the $\alpha_{2}$-adrenoceptor, has also been implicated in adipocyte proliferation (Bouloumie et al. 1994; Valet et al. 1998). Specifically, increases in adipocyte $\alpha_{2}$-adrenoceptor number precede the marked increase in FCN after surgical denervation of WAT (Cousin et al. 1993). The exact chain of events linking the increase in $\alpha_{2}$-adrenoceptor number and stimulation of these receptors with the increase in fat cell proliferation is not known, but one possibility involves a compensatory increase in adrenal medullary catecholamine secretion that occurs after sympathetic nerve denervation (Takahashi et al. 1993). The steps beyond the stimulation of $\alpha$-adrenoceptors resulting in this proliferation are not well understood, but locally released lysophosphatidic acid (Valet et al. 1998), a glycerophospholipid (Newsholme \& Leech, 1983), may be involved. Agonists of the $\alpha_{2}$-adrenoceptor trigger a rapid and prolonged release of lysophosphatidic in isolated WAT cells (Valet et al. 1998) and, moreover, lysophosphatidic acid added to preadipose cell lines triggers fat cell proliferation (Valet et al. 1998). Finally, the newly-discovered white adipocyte paracrine factor autotoxin (a type II ecto-nucleotide pyrophosphatase phosphodiesterase) may in turn stimulate proliferation via the release of lysophosphatidic acid (Ferry et al. 2003). Clearly, a deeper understanding of the mechanisms involved in fat cell proliferation in general, and the modulation of fat cell proliferation by the SNS specifically, requires further investigation.

\section{Sympathetic nervous system outflow from brain can control the release of white adipose tissue-secreted peptides}

Leptin is a cytokine that is synthesized and released primarily by white adipocytes (Maffei et al. 1995), and its discovery (Zhang et al. 1994) led to the notion that leptin informs the brain of body fat levels. This view, now considered dogmatic, is largely based on the frequent positive correlation between circulating leptin concentrations and the extent of adiposity (e.g. man (Considine et al. 1996; Dua et al. 1996; Ostlund et al. 1996) and laboratory mice (Frederich et al. 1995)); but leptin is also involved in other functions (e.g. reproduction, immunology; stress; for review, see Harris, 2000). There is an ever increasing number of exceptions to the positive correlation between body fat levels and circulating leptin concentration, suggesting that leptin might not be viewed as a perfect signal of adiposity.

The SNS outflow from the brain to WAT has been proposed as a principal controller of the secretion of leptin (Trayhurn et al. 1998). This view stems largely from the findings that conditions promoting increased SNS drive to WAT, such as cold exposure (Trayhurn et al. 1995) and fasting (Hardie et al. 1996), or direct stimulation of WAT $\beta$-adrenoceptors by receptor agonists (Mantzoros et al. 1996; Trayhurn et al. 1996) inhibit leptin gene expression and/or secretion. Conversely, disruption of the SNS drive to WAT via the catecholaminergic neurotoxin 6-hydroxydopamine or via $\alpha$-methyl- $p$-tyrosine, a blocker of catecholamine (noradrenaline) synthesis, increases circulating leptin concentrations (Rayner et al. 1998; Sivitz et al.
1999). Collectively, these data support a primary role for the SNS innervation of WAT in leptin synthesis or release (increases in sympathetic drive decrease, and decreases in sympathetic drive increase, the synthesis or release of leptin).

\section{Does white adipose tissue have parasympathetic nervous system innervation?}

Recently, it has been reported that WAT has PSNS innervation (Kreier et al. 2002). This view is based largely on the presence of PRV-infected neurons in traditionallyaccepted origins of PSNS premotor neurons, such as the dorsal vagal complex of the brainstem, after injections of the virus into WAT (Kreier et al. 2002). Such PRVlabelled neurons in this 'PSNS' area after injections into WAT have been reported (Bamshad et al. 1998), but they were attributed rogue SNS outflow neurons because the notion of wholly SNS or PSNS areas or nuclei in the brain has not withstood the test of time (for example, see Kalia et al. 1984; Gwyn et al. 1985). In addition, it is contended that WAT PSNS surgical denervation can be done selectively at the level of the WAT pad (Kreier et al. 2002). After this denervation, and in combination with a hyperinsulinaemic euglycaemic clamp, insulin-mediated glucose and NEFA uptake is reduced by approximately $30 \%$, with hormone-sensitive lipase activity (involved in the hydrolysis of triacylglycerol) increased by approximately $50 \%$ (Kreier et al. 2002). Reductions in catabolic responses as a result of the presumed PSNS denervation of WAT suggest that the function of this parasympathetic innervation is to oppose the SNS catabolic actions in the tissue (Kreier et al. 2002), in much the same manner that these two innervations oppose one another in function in other tissues (e.g. heart). There is no corroborating neurochemical evidence to show that the phenotype of these neurons includes acetylcholine, the predominant PSNS postganglionic neurotransmitter, nor biochemical evidence for the acetylcholinesterase, an enzyme important in the degradation of acetylcholine (Ballantyne, 1968). Thus, the presence in WAT of vesicular acetylcholine transporter, a marker of PSNS innervation (for example, see Schafer et al. 1998), has recently been investigated (A Giradano, K Song, $\mathrm{T}$ Bartness and S Cinti, unpublished results). No vesicular acetylcholine transporter immunoreactivity has been found refuting possible PSNS innervation, as has been previously suggested (Kreier et al. 2002; for comparison, see Ballantyne, 1968; Bartness, 2002). Finally, preliminary studies have investigated the hypothesis that if first the SNS innervation of WAT is selectively eliminated and then the PRV injected, PSNS innervation should be preserved and infections of the PSNS outflow to WAT should be unabated. Thus, WAT was locally sympathetically denervated via injections of the catecholaminergic neurotoxin 6-hydroxy-dopamine, followed a few days later by injections of the PRV. In 6-hydroxy-dopamineinjected animals no PRV-infected cells were found anywhere in the brain, whereas the normal labelling of SNS outflow neurons by the virus was seen in hamsters injected with the 6-hydroxy-dopamine vehicle (A Giradano, $\mathrm{K}$ Song, $\mathrm{T}$ Bartness and $\mathrm{S}$ Cinti, unpublished results). Thus, these and other data discussed earlier raise some 
doubt as to the presence of PSNS innervation of WAT. Such innervation would be intriguing, however, and would afford WAT the neural control possessed by most other organs.

White adipose tissue also has sensory innervation that probably interacts with its sympathetic nervous system innervation

Sensory-motor innervation of tissues is the rule, not the exception; so it should not be surprising that there is sensory innervation of WAT (for reviews, see Bartness \& Bamshad, 1998; Bartness et al. 2001). Sensory innervation of WAT was initially suggested by the identification of substance P in WAT (Fredholm, 1985). Substance P and CGRP are contained within, and released from, sensory neurons and thus are considered markers of sensory innervation (Hill et al. 1996). This initial biochemical analysis has been confirmed more recently using immunohistochemistry, showing that WAT contains CGRP- and substance P-immunoreactivity (Giordano et al. 1996). Direct evidence of the sensory innervation of WAT was first shown neuroanatomically when crystals of the fluorescent anterograde tract tracer True Blue were implanted in rat WAT, resulting in labelled bipolar sensory neurons in the dorsal root ganglia (Fishman \& Dark, 1987). The functions of this sensory innervation of WAT are not well understood. One function involves the ability of leptin to increase peripheral SNS activity, as measured electrophysiologically; i.e. injections of leptin into one epididymal WAT pad increase sensory nerve firing rates from that epididymal WAT pad, while simultaneously increasing the sympathetic nerve activity of the contralateral epididymal WAT pad (Niijima, 1998). These data suggest that sensory nerves may possess leptin receptors, and that their activation could send afferent signals from WAT to the CNS via sensory nerves to trigger increases in the SNS outflow to WAT, thereby increasing lipolysis.

Another possible function of the WAT sensory innervation is its involvement in a negative feedback system that regulates lipid mobilization or accumulation through modification of the SNS drive to WAT. This view (Bartness \& Bamshad, 1998) suggests interplay between sympathetic and sensory nerves to and from WAT respectively, and is based on evidence for such interactions in other tissues. For example, global sympathectomy or surgical denervation markedly increases CGRP immunoreactivity in the mesenteric and other vascular beds, as well as in most organs (Mione et al. 1992; Aberdeen et al. 1990). Conversely, a reciprocal response occurs after global sensory denervation, resulting in increases in sympathetic activity measured electrophysiologically (Ralevic et al. 1995).

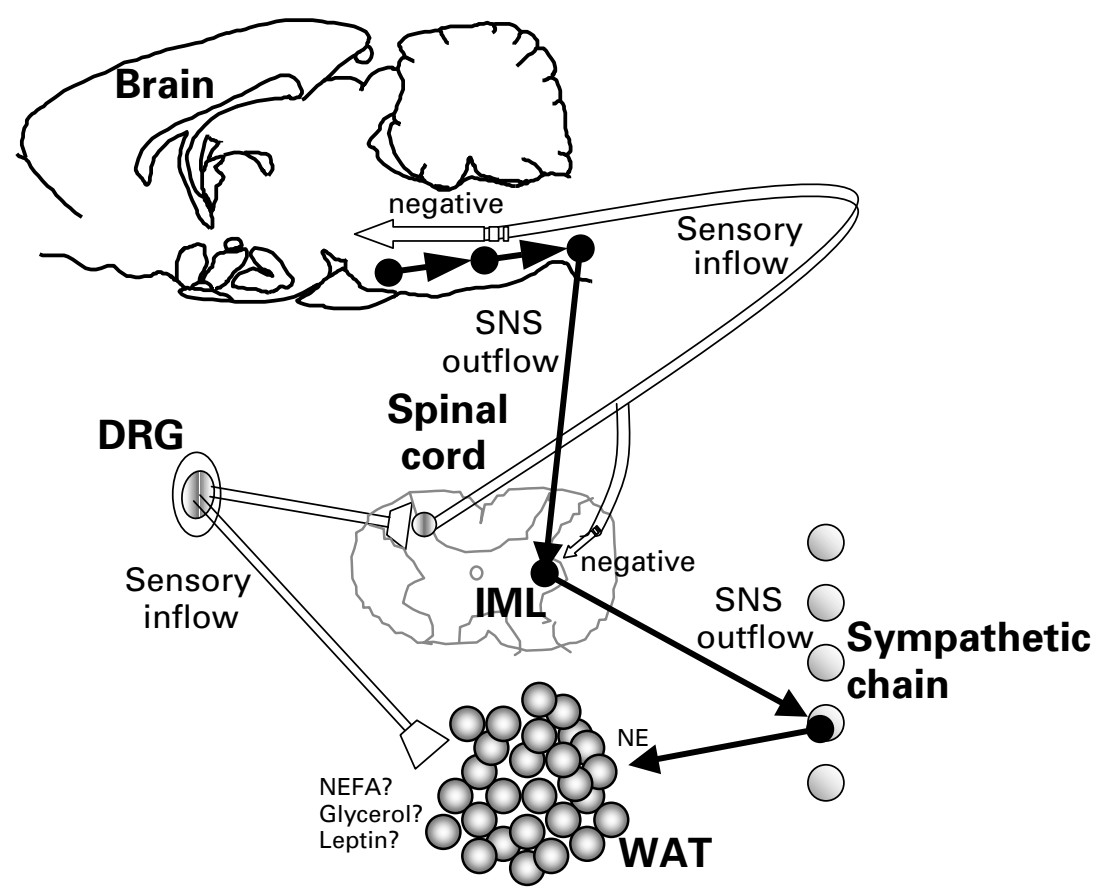

Fig. 3. Schematic diagram of hypothesized neural interplay between the sympathetic nervous system (SNS) outflow from brain to white adipose tissue (WAT). Sensory input $(\diamond)$ detects WAT substance indicative of the amount of lipid and/or its turnover, perhaps NEFA, glycerol or leptin via dorsal root ganglion (DRG) bipolar sensory neurons. Sensory information goes to spinal cord and then on to the brain to interact with the SNS outflow and/or a short-feedback loop may go to the intermedial lateral (IML) horn of the spinal cord; in either or both cases the sensory innervation performs as a negative feedback to the SNS innervation of WAT. The SNS outflow from brain to WAT $(\leftarrow)$ promotes lipolysis and inhibits fat cell proliferation via its principal postganglionic neurotransmitter, noradrenaline (NE). The sensory nerves may also or instead provide the brain with feedback about the lipid stores in WAT. 
These and other studies (for review, see Rubino et al. 1997) suggest cross talk between the sympathetic and sensory innervations of tissues and, based on these data, it is speculated that the sensory nerves innervating WAT may participate in a feedback loop to regulate the level of its sympathetic drive, thereby regulating lipolysis (Bartness \& Bamshad, 1998).

\section{Conclusions, speculations and future directions}

WAT clearly has SNS and sensory innervation, with some data suggesting PSNS innervation (Kreier et al. 2002). As for the purported PSNS innervation of WAT, tract tracing showing innervation from dorsal vagal complex neurons to WAT that also express a PSNS neurochemical marker (e.g. acetylcholine, NO, vasoactive intestinal peptide) are needed, as well as functional studies such as electrical or chemical stimulation of these neurons to elicit responses from WAT that are the opposite of, or oppose, those of SNS activation.

Finally, the depth of the understanding of the function of the sensory afferent nerves emanating from WAT is certainly in its infancy. As noted earlier, it is believed that one of these mechanisms is to inform the brain of WAT pad lipid levels as local selective sensory denervation of WAT using capsaicin (H Shi and T Bartness, unpublished results) results in the reparation of the lipid deficit by lipid accretion in the other fat pads similar to that if the capsaicin-injected fat pads had been physically removed. Furthermore, anterograde trans-synaptic viral tract tracing is required to determine which areas of the brain receive this sensory innervation.

Collectively, the innervation of WAT by several types of neurons cannot be challenged, nor can its importance be underestimated. Additional roles for these innervations, especially for the control of the synthesis and release of WAT factors are extremely likely (e.g. leptin, adiponectin, TNF- $\alpha$ (Orban et al. 1999), which are important in lipolysis and fat cell proliferation. Understanding the roles of the sensory innervation of WAT and its interactions with the SNS innervation should also increase with a more detailed neuroanatomy of the sensory innervation. The differential activation of SNS outflow circuits to WAT and other energy-related sympathetic targets such as brown adipose tissue, as well as the differential SNS drives across WAT pads, should also prove enlightening. A schematic diagram of the cross talk between the SNS and sensory innervations of WAT is depicted in Fig. 3.

\section{Acknowledgements}

This research was supported by National Institute of Health R01-DK35254 to T.J.B. The authors thank Dr Ruth Harris for her critical reading of this manuscript.

\section{References}

Aberdeen J, Corr L, Milner P, Lincoln J \& Burnstock G (1990) Marked increase in calcitonin gene-related peptide containing nerves in the developing rat following long-term sympathectomy with guanethidine. Neurosciences 35, 175-184.
Ainsworth A, Halim P, Wall PD, Allt G, Mackenzie M, Gibson S \& Polak J (1981) Effects of capsaicin applied locally to adult peripheral nerves. II. Anatomy and enzyme and peptide chemistry of peripheral nerve and spinal cord. Pain 11, 379-388.

Ballantyne B (1968) Histochemical and biochemical aspects of cholinesterase activity of adipose tissue. Archives Internationales de Pharmacodynamie et de Therapie 173, 343-350.

Ballantyne B \& Raftery AT (1974) The intrinsic autonomic innervation of white adipose tissue. Cytobios 10, 187-197.

Ballard K, Malmfors T \& Rosell S (1974) Adrenergic innervation and vascular patterns in canine adipose tissue. Microvascular Research 8, 164-171.

Bamshad M, Aoki VT, Adkison MG, Warren WS \& Bartness TJ (1998) Central nervous system origins of the sympathetic nervous system outflow to white adipose tissue. American Journal of Physiology 275, R291-R299.

Bamshad M, Song CK \& Bartness TJ (1999) CNS origins of the sympathetic nervous system outflow to brown adipose tissue. American Journal of Physiology 276, R1569-R1578.

Bartness TJ (1995) Short day-induced depletion of lipid stores is fat pad- and gender-specific in Siberian hamsters. Physiology and Behavior 58, 539-550.

Bartness TJ (1996) Photoperiod, sex, gonadal steroids and housing density affect body fat in hamsters. Physiology and Behavior 60, 517-529.

Bartness TJ (2002) Dual innervation of white adipose tissue: some evidence for parasympathetic nervous system involvement. Journal of Clinical Investigation 110, 1235-1237.

Bartness TJ \& Bamshad M (1998) Innervation of mammalian white adipose tissue: implications for the regulation of total body fat. American Journal of Physiology 275, R1399-R1411.

Bartness TJ, Demas GE \& Song CK (2001) Central nervous system innervation of white adipose tissue. In Adipose Tissue, pp. 116-130 [S Klaus, editor]. Georgetown, TX: Landes Bioscience.

Bartness TJ, Demas GE \& Song CK (2002) Seasonal changes in adiposity: the roles of the photoperiod, melatonin and other hormones and the sympathetic nervous system. Experimental Biology and Medicine 227, 363-376.

Bartness TJ \& Fine JB (1999) Melatonin and seasonal changes in body fat. In Melatonin in the Promotion of Health, pp. 115-135 [RR Watson, editor]. Boca Raton, FL: CRC.

Bartness TJ \& Goldman BD (1988) Peak duration of serum melatonin and short day responses in adult Siberian hamsters. American Journal of Physiology 255, R812-R822.

Bartness TJ \& Goldman BD (1989) Mammalian pineal melatonin: A clock for all seasons. Experientia 45, 939-945.

Bartness TJ, Goldman BD \& Bittman EL (1991) SCN lesions block responses to systemic melatonin infusions in Siberian hamsters. American Journal of Physiology 260, R102-R112.

Bartness TJ, Hamilton JM, Wade GN \& Goldman BD (1989) Regional differences in fat pad responses to short days in Siberian hamsters. American Journal of Physiology 257, R1533-R1540.

Bartness TJ \& Wade GN (1985) Photoperiodic control of seasonal body weight cycles in hamsters. Neuroscience and Behavioral Reviews 9, 599-612.

Bouloumie A, Planat V, Devedjian JC, Valet P, Saulnier-Blache JS, Record M \& Lafontan M (1994) Alpha 2-adrenergic stimulation promotes preadipocyte proliferation. Involvement of mitogen-activated protein kinases. Journal of Biological Chemistry 269, 30254-30259.

Bray GA (1990) Obesity - a state of reduced sympathetic activity and normal or high adrenal activity (the autonomic and adrenal hypothesis revisited). International Journal of Obesity 14, 77-91. 
Bray GA (1991) Obesity, a disorder of nutrient partitioning: the MONA LISA hypothesis. Journal of Nutrition 121, 1146-1162.

Bray GA \& Nishizawa Y (1978) Ventromedial hypothalamus modulates fat mobilisation during fasting. Nature 274, 900-901.

Butler AA \& Cone RD (2002) The melanocortin receptors: lessons from knockout models. Neuropeptides 36, 77-84.

Cannon WB (1939) The Wisdom of the Body. New York: Norton.

Cantu RC \& Goodman HM (1967) Effects of denervation and fasting on white adipose tissue. American Journal of Physiology 212, 207-212.

Card JP, Rinaman L, Schwaber JS, Miselis RR, Whealy ME, Robbins ME \& Enquist LW (1990) Neurotropic properties of pseudorabies virus: uptake and transneuronal passage in the rat central nervous system. Journal of Neuroscience $\mathbf{1 0}$, 1974-1994.

Castan I, Valet P, Larrouy D, Voisin T, Remaury A, Daviaud D, Laburthe M \& Lafontan M (1993) Distribution of PYY receptors in human fat cells: an antilipolytic system alongside the alpha2-adrenergic system. American Journal of Physiology 265, E74-E80.

Castan K, Valet P, Quideau N, Voisin T, Ambid L, Laburthe M, Lafontan M \& Carpene C (1994) Antilipolytic effects of alpha2-adrenergic agonists, neuropeptide Y, adenosine, and PGE1 in mammal adipocytes. American Journal of Physiology 266, R1141-R1147.

Clement G (1950) La mobilisation des glycerides de reserve chez le rat. II. Influence due systeme nerveux sympathique. Etablissement d'un procede de mesure de I'intensite de la mobilisation (The mobilisation of glyceride reserves in the rat. II. Influence of the sympathetic nervous system. Establishing a process for measuring the intensity of the mobilisation). Archives de Sciences Physiologiques 4, 13-29.

Considine RV, Considine EL, Williams CJ, Hyde TM \& Caro JF (1996) The hypothalamic leptin receptor in humans: identification of incidental sequence polymorphisms and absence of the $\mathrm{db} / \mathrm{db}$ mouse and fa/fa rat mutations. Diabetes 45, 992-994.

Cousin B, Casteilla L, Lafontan M, Ambid L, Langin D, Berthault M-F \& Penicaud L (1993) Local sympathetic denervation of white adipose tissue in rats induces preadipocyte proliferation without noticeable changes in metabolism. Endocrinology 133, 2255-2262.

Daniel H \& Derry DM (1969) Criteria for differentiation of brown and white fat in the rat. Canadian Journal of Physiology and Pharmacology 47, 941-945.

Demas GE \& Bartness TJ (2001a) Novel method for localized, functional sympathetic nervous system denervation of peripheral tissue using guanethidine. Journal of Neuroscience Methods 112, 21-28.

Demas GE \& Bartness TJ (2001b) Direct innervation of white fat and adrenal medullary catecholamines mediate photoperiodic changes in body fat. American Journal of Physiology 281, R1499-R1505.

Diculescu I \& Stoica M (1970) Fluorescence histochemical investigations on the adrenergic innervation of the white adipose tissue in the rat. Journal of Neuro-visceral Relations 32, 25-36.

DiGirolamo M, Fine JB, Tagra K \& Rossmanith R (1998) Qualitative regional differences in adipose tissue growth and cellularity in male Wistar rats fed ad libitum. American Journal of Physiology 274, R1460-R1467.

Dodt C, Lonnroth P, Wellhoner JP, Fehm HL \& Elam M (2003) Sympathetic control of white adipose tissue in lean and obese humans. Acta Physiologica Scandinavica 177, 351-357.

Dogiel AS (1898) Die sensiblen Nervenendigungen im Herzen und in den Blutgefassen der Saugethiere (The afferent nerve endings in the heart and in the blood vessels of mammals). Archiv für Mikroskopischen Anatomie 52, 44-70.

Dua A, Hennes MI, Hoffmann RG, Maas DL, Krakower GR, Sonnenberg GE \& Kissebah AH (1996) Leptin: a significant indicator of total body fat but not of visceral fat and insulin insensitivity in African-American women. Diabetes 45, 1635-1637.

Dulloo AG \& Miller DS (1987) Obesity: a disorder of the sympathetic nervous system. World Review of Nutrition and Dietetics 50, 1-56.

Edwards SL, Anderson CR, Southwell BR \& McAllen RM (1996) Distinct preganglioinic neurons innervate noradrenaline and adrenaline cells in the cat adrenal medulla. Neurosciences 70, 825-832.

Enquist LW \& Card JP (2003) Recent advances in the use of neurotropic viruses for circuit analysis. Current Opinion in Neurobiology 13, 603-606.

Faust IM (1984) Role of the fat cell in energy balance physiology. In Eating and Its Disorders, pp. 97-107 [AJ Stunkard and E Stellar, editors]. New York: Raven Press.

Ferry G, Tellier E, Try A, Gres S, Naime I, Simon MF et al. (2003) Autotaxin is released from adipocytes, catalyzes lysophosphatidic acid synthesis, and activates preadipocyte proliferation. Up-regulated expression with adipocyte differentiation and obesity. Journal of Biological Chemistry 278, 18162-18169.

Fishman RB \& Dark J (1987) Sensory innervation of white adipose tissue. American Journal of Physiology 253, R942R944.

Frederich RC, Lollmann B, Hamann A, Napolitano-Rosen A, Kahn BB, Lowell BB \& Flier JS (1995) Expression of ob mRNA and its encoded protein in rodents. Impact of nutrition and obesity. Journal of Clinical Investigation 96, $1658-1663$.

Fredholm BB (1985) Nervous control of circulation and metabolism in white adipose tissue. In New Perspectives in Adipose Tissue: Structure, Function and Development, pp. 45-64 [A Cryer and RLR Van, editors]. Boston, MA: Butterworth.

Garofalo MAR, Kettelhut IC, Roselino JES \& Migliorini RH (1996) Effect of acute cold exposure on norepinephrine turnover rates in rat white adipose tissue. Journal of the Autonomic Nervous System 60, 206-208.

Gasteyger C \& Tremblay A (2002) Metabolic impact of body fat distribution. Journal of Endocrinological Investigation 25, 876-883.

Giordano A, Morroni M, Santone G, Marchesi GF \& Cinti S (1996) Tyrosine hydroxylase, neuropeptide Y, substance P, calcitonin gene-related peptide and vasoactive intestinal peptide in nerves of rat periovarian adipose tissue: an immunohistochemical and ultrastructural investigation. Journal of Neurocytology 25, 125-136.

Gold RM (1973) Hypothalamic obesity: the myth of the ventromedial nucleus. Science 182, 488-490.

Gold RM, Jones AP \& Sawchenko PE (1977) Paraventricular area: critical focus of a longitudinal neurocircuitry mediating food intake. Physiology and Behavior 18, 1111-1119.

Gwyn DG, Ritchie TC \& Coulter JD (1985) The central distribution of vagal catecholaminergic neurons which project into the abdomen in the rat. Brain Research 328, 139-144.

Hardie LJ, Rayner DV, Holmes S \& Trayhurn P (1996) Circulating leptin levels are modulated by fasting, cold exposure and insulin administration in lean but not Zucker (fa/fa) rats as measured by ELISA. Biochemical and Biophysical Research Communications 223, 660-665.

Harris RBS (2000) Leptin - much more than a satiety signal. Annual Review of Nutrition 20, 45-75.

Haskell-Luevano C, Miwa H, Dickinson C, Hruby VJ, Yamada T \& Gantz I (1994) Binding and cAMP studies of melanotropin 
peptides with the cloned human peripheral melanocortin receptor, hMC1R. Biochemical and Biophysical Research Communications 204, 1137-1142.

Hausman DB, DiGirolamo M, Bartness TJ, Hausman GJ \& Martin RJ (2001) The biology of white adipocyte proliferation. Obesity Reviews 2, 239-254.

Hill B, Ralevic V, Crowe R \& Burnstock G (1996) Innervation and nitric oxide modulation of mesenteric arteries of the Golden hamster. European Journal of Pharmacology 317, 275-283.

Hillarp NA \& Hokfelt B (1953) Evidence of adrenaline and noradrenaline in separate adrenal medullary cells. Acta Physiologica Scandinavica 30, 55-68.

Hoffman GE, Smith MS \& Verbalis JG (1993) c-Fos and related immediate early gene products as markers of activity in neuroendocrine systems. Frontiers in Neuroendocrinology $\mathbf{1 4}$, 173-213.

Hwa JJ, Ghibaudi L, Gao J \& Parker EM (2001) Central melanocortin system modulates energy intake and expenditure of obese and lean Zucker rats. American Journal of Physiology 281, R444-R451.

Jansco G, Kiraly E \& Jansco-Gabor A (1980) Direct evidence for an axonal site of action of capsaicin. Naunyn Schmiedeburgs Archives of Pharmacology 31, 91-94.

Janssen I, Fortier A, Hudson R \& Ross R (2002) Effects of an energy-restrictive diet with or without exercise on abdominal fat, intermuscular fat, and metabolic risk factors in obese women. Diabetes Care 25, 431-438.

Jones DD, Ramsay TG, Hausman GJ \& Martin RJ (1992) Norepinephrine inhibits rat pre-adipocyte proliferation. International Journal of Obesity 16, 349-354.

Kalia M, Fuxe K, Goldstein M, Harfstrand A, Agnati LF \& Coyle JT (1984) Evidence for the existence of putative dopamine-, adrenaline- and noradrenaline-containing vagal motor neurons in the brainstem of the rat. Neuroscience Letters 50, 57-62.

Kirtland J \& Gurr MI (1979) Adipose tissue cellularity: a review 2 . The relationship between cellularity and obesity. International Journal of Obesity 3, 15-55.

Kras KM, Hausman DB, Hausman GJ \& Martin RJ (1999) Adipocyte development is dependent upon stem cell recruitment and proliferation of preadipocytes. Obesity Research 7, 491-497.

Kreier F, Fliers E, Voshol PJ, Van Eden CG, Havekes LM, Kalsbeek A, Van Heijningen CL, Sluiter AA, Mettenleiter TC, Romijn JA, Sauerwein HP \& Buijs RM (2002) Selective parasympathetic innervation of subcutaneous and intra-abdominal fat - functional implications. Journal of Clinical Investigation 110, 1243-1250.

Lafontan M \& Berlan M (1993) Fat cell adrenergic receptors and the control of white and brown fat cell function. Journal of Lipid Research 34, 1057-1091.

Lazzarini SJ \& Wade GN (1991) Role of sympathetic nerves in effects of estradiol on rat white adipose tissue. American Journal of Physiology 260, R47-R51.

Luiten PGM, ter Horst GJ, Karst H \& Steffens AB (1985) The course of paraventricular hypothalamic efferents to autonomic structures in medulla and spinal cord. Brain Research 329, 374-378.

Maffei M, Fei H, Lee GH, Dani C, Leroy P, Zhang Y, Proenca R, Negrel R, Ailhaud G \& Friedman JM (1995) Increased expression in adipocytes of ob RNA in mice with lesions of the hypothalamus and with mutations at the $\mathrm{db}$ locus. Proceedings of the National Academy of Sciences USA 92, 6957-6960.

Mantzoros CS, Qu DQ, Frederich RC, Susulic VS, Lowell BB, Maratos-Flier E \& Flier JS (1996) Activation of $\beta_{3}$ adrenergic receptors suppresses leptin expression and mediates a leptin-independent inhibition of food intake in mice. Diabetes 45, 909-914.

Mauer MM \& Bartness TJ (1996) Photoperiod-dependent fat pad mass and cellularity changes following partial lipectomy in Siberian hamsters. American Journal of Physiology 270, R383-R392.

Migliorini RH, Garofalo MAR \& Kettelhut IC (1997) Increased sympathetic activity in rat white adipose tissue during prolonged fasting. American Journal of Physiology 272, R656-R661.

Mione M, Cavanagh JFR, Kirkpatrick KA \& Burnstock G (1992) Plasticity in expression of calcitonin gene-related peptide and substance $\mathrm{P}$ immunoreactivity in ganglia and fibres following guanethidine and/or capsaicin denervation. Cell Tissue Research 268, 491-504.

Morrison SF (2001) Differential control of sympathetic outflow. American Journal of Physiology 281, R683-R698.

Newsholme EA \& Leech AR (1983) Biochemistry for the Medical Sciences. Chichester, West Sussex: John Wiley.

$\mathrm{Ng}$ TB \& Wong CM (1986) Effects of pineal indoles and arginine vasotocin on lipolysis and lipogenesis in isolated adipocytes. Journal of Pineal Research 3, 55-66.

Niijima A (1998) Afferent signals from leptin sensors in the white adipose tissue of the epididymis, and their reflex effect in the rat. Journal of the Autonomic Nervous System 73, 19-25.

Nishizawa Y \& Bray GA (1978) Ventromedial hypothalamic lesions and the mobilization of fatty acids. Journal of Clinical Investigation 61, 714-721.

Ollmann MM, Wilson BD, Yang YK, Kerns JA, Chen Y, Gantz I \& Barsh GS (1997) Antagonism of central melanocortin receptors in vitro and in vivo by agouti-related protein. Science 278, 135-138.

Orban Z, Remaley AT, Sampson M, Trajanoski Z \& Chrousos GP (1999) The differential effect of food intake and betaadrenergic stimulation on adipose-derived hormones and cytokines in man. Journal of Clinical Endocrinology and Metabolism 84, 2126-2133.

Ostlund RE Jr, Yang JW, Klein S \& Gingerich R (1996) Relation between plasma leptin concentration and body fat, gender, diet, age, and metabolic covariates. Journal of Clinical Endocrinology and Metabolism 81, 3909-3913.

Ozaki N, Sugiura Y, Yamamoto M \& Nishiyama Y (1996) Induction of Fos protein expression in spinal cord neurons by herpes simplex virus infections in the mouse. Neuroscience Letters 216, 61-64.

Pasanisi F, Contaldo F, de Simone G \& Mancini M (2001) Benefits of sustained moderate weight loss in obesity. Nutrition Metabolism and Cardiovascular Diseases 11, 401-406.

Powley TL, Walgren MC \& Laughton WB (1983) Effects of guanethidine sympathectomy on ventromedial hypothalamic obesity. American Journal of Physiology 245, R408-R420.

Ralevic V, Karoon P \& Burnstock G (1995) Long-term sensory denervation by neonatal capsaicin treatment augments sympathetic neurotransmission in rat mesenteric arteries by increasing levels of norepinephrine and selectively enhancing postjunctional actions. Journal of Pharmacology and Experimental Therapeutics 274, 64-71.

Raposinho PD, White RB \& Aubert ML (2003) The melanocortin agonist melanotan-II reduces the orexigenic and adipogenic effects of neuropeptide Y (NPY) but does not affect the NPYdriven suppressive effects on the gonadotropic and somatotropic axes in the male rat. Journal of Neuroendocrinology 15, 173-181.

Rayner DV, Simon E, Duncan JS \& Trayhurn P (1998) Hyperleptinaemia in mice induced by administration of the tyrosine hydroxylase inhibitor alpha-methyl-p-tyrosine. FEBS Letters 429, 395-398. 
Rebuffe-Scrive M (1991) Neuroregulation of adipose tissue: molecular and hormonal mechanisms. International Journal of Obesity 15, 83-86.

Rizack MA (1961) An epinephrine-sensitive lipolytic activity in adipose tissue. Journal of Biological Chemistry 236, 657-662.

Robidoux J, Pirouzi P, Lafond J \& Savard R (1995) Site-specific effects of sympathectomy on the adrenergic control of lipolysis in hamster fat cells. Canadian Journal of Physiology and Pharmacology 73, 450-458.

Rubino A, Ralevic V \& Burnstock G (1997) Sympathetic neurotransmission in isolated rat atria after sensory-motor denervation by neonatal treatment with capsaicin. Journal of Pharmacology and Experimental Therapeutics 282, 671-675.

Schafer MK, Eiden LE \& Weihe E (1998) Cholinergic neurons and terminal fields revealed by immunohistochemistry for the vesicular acetylcholine transporter. II. The peripheral nervous system. Neuroscience 84, 361-376.

Shi H \& Bartness TJ (2001) Neurochemical phenotype of sympathetic nervous system outflow from brain to white fat. Brain Research Bulletin 54, 375-385.

Shi H, Giordano A, Cinti S \& Bartness TJ (2005) Sensory or sympathetic white adipose tissue denervation differentially affects depot growth and cellularity. American Journal of Physiology (In the Press).

Sivitz WI, Fink BD, Morgan DA, Fox JM, Donohoue PA \& Haynes WG (1999) Sympathetic inhibition, leptin, and uncoupling protein subtype expression in normal and fasting rats. American Journal of Physiology 277, E668-E677.

Skofitsch G \& Jacobowitz DM (1985) Calcitonin gene-related peptide coexists with substance $\mathrm{P}$ in capsaicin sensitive neurons and sensory ganglia of the rat. Peptides 6, 747-754.

Slavin BG \& Ballard KW (1978) Morphological studies on the adrenergic innervation of white adipose tissue. Anatomical Record 191, 377-389.

Song CK \& Bartness TJ (1996) The effects of anterior hypothalamic lesions on short-day responses in Siberian hamsters given timed melatonin infusions. Journal of Biological Rhythms 11, 14-26.

Song CK \& Bartness TJ (1998) Dorsocaudal SCN microknifecuts do not block short day responses in Siberian hamsters given melatonin infusions. Brain Research Bulletin 45, 239-246.

Song CK \& Bartness TJ (2001) CNS sympathetic outflow neurons to white fat that express melatonin receptors may mediate seasonal adiposity. American Journal of Physiology 281, R666-R672.

Strack AM \& Loewy AD (1990) Pseudorabies virus: a highly specific transneuronal cell body marker in the sympathetic nervous system. Journal of Neuroscience 10, 2139-2147.

Strack AM, Sawyer WB, Platt KB \& Loewy AD (1989) CNS cell groups regulating the sympathetic outflow to adrenal gland as revealed by transneuronal cell body labeling with pseudorabies virus. Brain Research 491, 274-296.

Sved AF, Cano G \& Card JP (2001) Neuroanatomical specificity of the circuits controlling sympathetic outflow to different targets. Clinical and Experimental Pharmacology and Physiology 28, 115-119.

Takahashi A, Ikarashi Y, Ishimaru H \& Maruyama Y (1993) Compensation between sympathetic nerves and adrenal medullary activity: effects of adrenomedullation and chemical sympathectomy on catecholamine turnover. Life Sciences 53, $1567-1572$.
Takahashi A \& Shimazu T (1981) Hypothalamic regulation of lipid metabolism in the rat: effect of hypothalamic stimulation on lipolysis. Journal of the Autonomic Nervous System 4, 195-205.

Trayhurn P, Duncan JS, Hoggard N \& Rayner DV (1998) Regulation of leptin production: a dominant role for the sympathetic nervous system. Proceedings of the Nutrition Society 57, 413-419.

Trayhurn P, Duncan JS \& Rayner DV (1995) Acute cold-induced suppression of $o b$ (obese) gene expression in white adipose tissue of mice: mediation by the sympathetic nervous system. Biochemical Journal 311, 729-733.

Trayhurn P, Duncan JS, Rayner DV \& Hardie LJ (1996) Rapid inhibition of ob gene expression and circulating leptin levels in lean mice by the beta 3-adrenoceptor agonists BRL 35135A and ZD2079. Biochemical and Biophysical Research Communications 228, 605-610.

Turek FW \& Campbell CS (1979) Photoperiodic regulation of neuroendocrine-gonadal activity. Biology of Reproduction 20, 32-50.

Turtzo LC, Marx R \& Lane MD (2001) Cross-talk between sympathetic neurons and adipocytes in coculture. Proceedings of the National Academy of Sciences USA 98, 12385-12390.

Underwood H \& Goldman BD (1987) Vertebrate circadian and photoperiodic systems: role of the pineal gland and melatonin. Journal of Biological Rhythms 2, 279-315.

Vague J, Vague P, Tramoni M, Vialettes B \& Mercier P (1980) Obesity and diabetes. Acta Diabetologica Latina 17, 87-99.

Valet P, Pages C, Jeanneton O, Daviaud D, Barbe P, Record M, Saulnier-Blache JS \& Lafontan M (1998) Alpha 2-adrenergic receptor-mediated release of lysophosphatidic acid by adipocytes. A paracrine signal for preadipocyte growth. Journal of Clinical Investigation 101, 1431-1438.

Wade GN \& Bartness TJ (1984) Effects of photoperiod and gonadectomy on food intake, body weight and body composition in Siberian hamsters. American Journal of Physiology 246, R26-R30.

Weiss ML \& Chowdhury SI (1998) The renal afferent pathways in the rat: a pseudorabies virus study. Brain Research 812, 227-241.

White JE \& Engel FL (1958) A lipolytic action of epinephrine and norepinephrine on rat adipose tissue in vitro. Proceedings of the Society for Experimental Biology and Medicine 99, 375-378.

Wirsen C (1964) Adrenergic innervation of adipose tissue examined by fluorescence microscopy. Nature 202, 913.

Wright JT \& Hausman GJ (1990) Monoclonal antibodies against cell surface antigens expressed during porcine adipocyte differentiation. International Journal of Obesity 14, 284-291.

Young JB, Saville E, Rothwell NJ, Stock MJ \& Landsberg L (1982) Effect of diet and cold exposure on norepinephrine turnover in brown adipose tissue of the rat. Journal of Clinical Investigation 69, 1061-1071.

Youngstrom TG \& Bartness TJ (1995) Catecholaminergic innervation of white adipose tissue in the Siberian hamster. American Journal of Physiology 268, R744-R751.

Youngstrom TG \& Bartness TJ (1998) White adipose tissue sympathetic nervous system denervation increases fat pad mass and fat cell number. American Journal of Physiology 275, R1488-R1493.

Zhang Y, Proenca R, Maffei M, Barone M, Leopold L \& Friedman JM (1994) Positional cloning of the mouse obese gene and its human homologue. Nature 372, 425-432. 